\title{
Martínez y Mallarmé: El libro total en la nueva novela
}

\author{
Karolina Urbano ${ }^{1}$ \\ Universidad Nacional de Colombia \\ curbanog@gmail.com
}

Recibido: 30 - agosto - 2018 / Aceptado: 1 - octubres - 2018

\section{Resumen}

De la inmensa variedad intertextual que se encuentra en La nueva novela de Juan Luis Martínez, en este artículo se analiza la presencia de la poética de Mallarmé y cómo incide en el funcionamiento general de este polémico libro, especialmente en consonancia con la idea del Libro total que el poeta francés defendió. En La nueva novela subyace una idea de totalidad que permite hacer relación con la ambiciosa e imposible concepción del Libro total. También se muestra el conocimiento que Martínez tenía de los aportes realizados por Mallarmé: independencia del lenguaje poético y el fin de la representación, y la manera como el poeta chileno los presenta en la estructura formal de su libro experimental.

Palabras clave: libro total, visualidad, totalidad, intertexto.

\section{Abstract}

From the inmense intertextual variety presented on Juan Luis Martinez's $L a$ nueva novela, this article analyzes Mallarmés poetic presence and the way it influences the general fonction of this controversial book, being bonded to

1 Profesional en Filosofía y Letras por la Universidad de Caldas, Magíster en Filosofía por la Universidad Nacional de Colombia. Este artículo es un apartado de la tesis en curso para la Maestría en Literaturas Española y Latinoamericana de la Universidad de Buenos Aires, titulada La poética visual y política de Juan Luis Martínez: 
the idea of total book defended by the french poet. In La Nueva Novela an idea of totality is set up, being able to enhance an ambixious and impossible relationship between the conception of total Book. Also, Martinez's knowledge is shown along with the ideas given by Mallarmé: poetic language independence and the end of representation, and the way how the chilean poet presents these elements inside the formal structure of his experimental book.

Keywords: total book, visuality, totality, intertext. 
Invento una lengua que debe brotar necesariamente de una poética muy nueva Mallarmé

Pretendo un libro intolerable J.L. Martínez

\section{La nueva novela y la poesía visual}

$L$

a nueva novela es un libro experimental que nos remite a los géneros que surgieron gracias a prácticas mixtas como la poesía visual, género fronterizo entre la plástica y la literatura porque obliga dos tipos de lectura: la del signo lingüístico y de la imagen. Si bien en la antigüedad se encuentran indicios de poesía visual, los caligramas, por ejemplo, es a finales del siglo XIX cuando la relación imagen-texto representa el inicio de una nueva poética con el libro Un coup de dés jamais n'abolira le hasard (1897) del poeta francés Stéphane Mallarmé. La conciencia del espacio, el signo, la tipografía y la composición presentes en este poema, hacen que Mallarmé le devuelva al signo su materialidad y esto será la punta de lanza para las generaciones siguientes. Cuando se logra esta conciencia de la espacialidad del signo, el lector ya no va tras su contenido abstracto únicamente, pues "la imagen textualizada quiebra la linealidad del discurso" (Gache, 2006, p. 137) y el significado deja de estar separado de su disposición material, conforman una unidad. La palabra toma importancia como objeto. La conciencia de esto lleva a una transformación paradigmática de la poesía: es el fin de la representación. A partir de Mallarmé, las vanguardias de principios del siglo XX retoman y experimentan con este género: aparecen los caligramas de Apollinaire, Calligrammes (1918), Las palabras en libertad futuristas (1919) de Marinetti y los collages Dadá. En Latinoamérica encontramos los caligramas de Vicente Huidobro, como "El triángulo armónico" del libro Canciones en la noche (1913), 5 metros de poesia (1927) de Carlos Oquendo de Amat, entre otros.

Para la segunda mitad del siglo XX, la poesía visual ve la luz gracias a la Poesía Concreta y el Letrismo. Sin embargo, estos movimientos siguen ligados a las primeras vanguardias, a la experimentación con la tipografía, el collage y el libro como objeto artístico. A partir de los años 70 con las segundas vanguardias empieza otra relación entre la literatura y las artes plásticas, puesto que expresiones artísticas (instalación, performance, objet trouvé, etc), están más consolidadas, se introducen en la institución del arte, hacen parte del establishment que se pretendió superar en el momento de su aparición. Teniendo en cuenta los estudios de David Miralles (2004) y Mauricio Ríoseco (2013), algunos representantes de la neovanguardia en Chile son los poetas Raúl Zurita, Rodrigo Lira y Diego Maquieira.

Estos son algunos antecedentes al libro más importante de Martínez: La nueva novela, los cuales llevarían a cuestionar la originalidad de este libro que no fue muy 
bien recibido en su momento. No obstante, la densidad conceptual e intertextual, así como la forma en que incorpora lo visual, lo convierten sin duda en un caso aislado y único dentro de las letras chilenas de los años 80. En este artículo se intenta mostrar que detrás de esa complejidad recursiva de La nueva novela, se encuentra la influencia de Mallarmé, de su poética y de cierta relación con la idea del libro total.

La disposición textual es uno de los recursos más importantes en La nueva novela, por lo tanto, lo visual es un tema central. No se trata únicamente de una relación de la imagen con el texto, sino de un dispositivo (Agamben, 2011) capaz de alterar la recepción de los géneros. Sabemos que se trata de un libro que se inscribe dentro de la poesía chilena, pero que no contiene poemas en el sentido tradicional, que tiene el título de ser una novela sin serlo, que tampoco se trata de cuentos. El libro mantiene un formato para cada una de las intervenciones de cada página. Cada página tiene un título y un collage, o una intervención que configura una unidad. Esta tiene un significado individual, aunque interactúe a través de varios mecanismos (especialmente la cita o el pie de página) con otras páginas y sus respectivos contenidos. Más que hablar de poesía visual, se trata de una visualidad que sirve de alerta al lector para seguir un camino, un recorrido o simplemente de orientación ante una cantidad de información que parece caótica, que es a la vez todo y nada.

Por ejemplo, lo primero que percibimos en la portada es que hay dos nombres, como si fueran dos autores: Juan Luis Martínez y Juan de Dios Martínez, su alter ego, ambos tachados, que ambos estén tachados necesita de una marca que señala la negación y nos lleva a pensar en la negación del autor, el deseo del anonimato, el rechazo al nombre y la autoría como tal. Su visualidad, entonces, está en el texto atravesado por la línea, es la que informa la intención. En la portada vemos que todos sus elementos conducen a la idea de crisis: la foto de una casa de barrio destruyéndose como sucede en los terremotos, fenómeno frecuente en Chile. ${ }^{2}$ Pero no es un terremoto, es una inundación el desbordamiento de las aguas desestabiliza la tierra firme. Esta imagen de destrucción nos remite a otras metáforas: una analogía recurrente, especialmente en la época de las dictaduras en Latinoamérica, es la relación entre la casa y el país. El país como la casa se derrumba. De ahí en adelante hay una constante en el libro: ningún elemento está en su lugar, nada corresponde a lo que conocemos como "un libro de poesía". El título no es un índice de lo que vamos a encontrar en el contenido, el libro no es una novela en el sentido tradicional del género, tampoco podría ser nueva poesía o nueva narrativa. El libro se divide en siete partes o capítulos en los que no se narra una historia como tal, es un libro donde el texto se conjuga con la imagen y la página en blanco se convierte en algo más parecido al lienzo que a un simple material para contener palabras. Tipografía,

2 En la interpretación que da Araya (2006), no se trata de un terremoto sino de una inundación, por el agua que se puede observar encima de las casas. Sin embargo, no hay en la imagen de las casas presencia de agua. Solo de inestabilidad, de inminente caída. Quizás una ambigüedad propia de Martínez. 
fotografía, iconografía, texto e intertextualidad, es lo que encontramos página por página en un juego con el que Martínez quiere expresar que la poesía está en crisis. Al final del libro sabemos que todo se derrumba, lo que se ha desestabilizado es la realidad en su totalidad.

Esto lo que analiza Araya (2006) bajo el ítem de "la escritura", pues allí señala los recursos visuales, de los cuales resalta la falta de uniformidad del texto y, por esto, también es imagen. Los cambios en la tipografía y el uso de los signos de puntuación hacen que la página deba leerse y observarse con mucha atención. Podemos notar también una "composición gráfica más o menos homogénea" de una sola página para cada "texto" y siempre con los títulos en mayúscula, negrita y sin acentos.

La multiplicidad de recursos utilizados en La nueva novela da la impresión de un objeto inasible, inabordable en su manipulación como en la comprensión de su contenido. La cantidad de intertextos resulta una labor extenuante para quien quiera seguir la pista. Pero es precisamente esta idea la que Martínez quiere dar para que el libro tenga la apariencia de una totalidad: tanto en su contenido como en lo formal. Desde el contenido la totalidad estaría representada en todas las esferas del ámbito cognitivo humano: la ciencia, el arte, la literatura, la historia, la política. No siempre están explícitas estas esferas. En el caso de la ciencia, es más importante de lo que parece con la simple observación de los textos que se ocupan de las matemáticas, es con la escritura como reconocemos un aire de objetividad, de "cientificidad", especialmente en los títulos, subtítulos, notas, citas y epígrafes. En estos se juega con un lenguaje descriptivo (propio de la ciencia), con el soporte de la cita y/o epígrafe de una autoridad y la presentación del texto o imagen de manera esquemática, numerada, en lista, muchas veces a la manera de un silogismo. Algunos títulos muestran el tono "científico" o erudito que raya con la ironía y el absurdo: "Tania Savich y la fenomenología de lo redondo", "Primeras investigaciones sobre las burbujas en la superficie del café contenido en una taza" (Martínez, 1985 p. 112-114). Para Araya (2006, p. 6), este juego con la "escritura" muestra la polifonía del texto (en el sentido que le da Bajtin), porque no se presenta como un texto fijo y cerrado, sino abierto y en constante devenir debido a las interrupciones, espacios en blanco, cambio en la tipografía, etc. Las citas ponen al descubierto cierta erudición, pero como en Borges, es una trampa para el lector, el cual queda enfrentado a entenderlas como el soporte argumentativo que da la autoridad, o la duda de la autenticidad de la fuente o, incluso, de su existencia.

En la mayoría de los casos, a pesar del formato del texto, en la lectura nos percatamos de la cadencia y musicalidad de la poesía. Ignacio Valente (1977) considera que Martínez elimina el yo lírico y lo reemplaza con un lenguaje impersonal, axiomático, como en el lenguaje científico. De esta manera la poesía, entendida como la expresión de los sentimientos, se convierte en el pensamiento ontológico de la realidad. Pero es una fabulación de la realidad, así que predomina la ironía y el sinsentido. 
Con la presencia de estos recursos, Martínez logra una delimitación espacial en donde el contenido del mensaje debe ser leído (lectura de los signos), pero también visto (lectura de la imagen). Con la presentación formal de la prosa eleva los temas al descubrimiento de verdades acerca de las grandes preguntas del ser humano: el espacio, el tiempo, el lenguaje. Vemos, entonces que el proyecto de Martínez es tan ambicioso como excesivo, extravagante. Ambicioso en el contenido, literalmente quiere abarcar la totalidad (quizás por ello, el primer título era "Pequeña cosmogonía práctica"), y hay una incorporación de los recursos que va creciendo a lo largo del libro hasta saturarlo. La transgresión de Martínez en el uso de recursos finalmente satura el libro y lo desborda.

Este desbordamiento también se puede entender como un homenaje a sus "ídolos", muy al estilo de Martínez, en una aparente búsqueda por estar al mismo nivel que ellos: la ironía que predomina en La nueva novela en algunas ocasiones se transforma en la búsqueda del sinsentido a la manera de los juegos metafísicos propios de Lewis Carroll; el desbordamiento intertextual emulando a Borges, el desbordamiento máximo si lo comparamos con el ambicioso e imposible proyecto mallarmeano del libro total.

\section{La nueva novela y el libro total}

Las características de La nueva novela que nombramos al principio, como claves para ubicar el libro de Martínez dentro del contexto neovanguardista de su época, se pueden relacionar con las intenciones que cruzaban por la mente Mallarmé para construir su idea del Libro total: un libro que abarcaría la totalidad del mundo, porque el mundo era, en realidad, un libro, como señala Salvador Elizondo en la introducción de Stéphane Mallarmé (2008, p. 5):

Transcurrida entre 1842 y 1898 la vida de Mallarmé sólo registra un acontecimiento digno de ser tenido en cuenta: la revelación que tuvo en 1866 de que el mundo era un libro que él estaba escribiendo, obra pura sońada en la que se ocuparía hasta el fin de su vida.

Como si estuviera tras una ontología, Mallarmé pensaba en una idea de la poesía totalizadora y universal, su conciencia del lenguaje es similar a la búsqueda de algunos filósofos que ven la posibilidad de una simetría entre el lenguaje y el mundo, una equivalencia entre uno y otro. En este caso, no sería a través del lenguaje de la ciencia sino del lenguaje poético. Pero esta conciencia es una de las consignas básicas del Romanticismo y del Simbolismo, tendencia, esta última, en la que se identifica la poética de Mallarmé. Si bien es uno de los principales representantes del Simbolismo, Mallarmé significa un momento de ruptura, un referente de renovación poética de finales del siglo XIX, ya sea por la originalidad de su poética o como iniciador de una nueva apuesta por la poesía visual. En 1897, Mallarmé rompe con el canon poético con la publicación del poema "Un golpe de dados jamás abolirá el azar", en el cual encontramos: variación de la tipografía (mayúsculas, versales, redondas y 
cursivas), diferencia en el tamaño de la fuente, así como la alusión a los "blancos", la relación con una partitura y el prefacio al poema donde deja en claro sus intenciones. Es posible que tantos permisos fueran concedidos porque fue un texto que se publica por primera vez en una revista, en Cosmópolis. Al respecto dice Valery:

Mallarmé había estudiado muy cuidadosamente (incluso en los carteles, en los periódicos) la eficacia de las distribuciones de lo blanco y lo negro [cómo no acordarnos aquí de los colores que conforman un dado], la intención comparada de los tipos... En su sistema, una página debe, dirigiéndose al vistazo que precede y envuelve la lectura, intimar el movimiento de la composición; hacer presentir, por una especie de intuición material, por una armonía preestablecida las diferencias de marcha de nuestros sentidos, lo que va a producirse en la inteligencia. Introduce una lectura superficial que encadena la lectura lineal. (Citado por Liquete (2000) del libro Antología de Stephane Mallarmé, 1991).

Este poema será el inicio de una concepción de la poesía ambiciosa porque anhela a la totalidad y la universalidad. De ahí que la ruptura (un antes y un después) de la poética de Mallarmé se entiende desde dos aspectos centrales: en primer lugar, la idea totalizadora se encuentra en la pureza del poema, más exactamente, en la pureza del signo, lo cual tiene como consecuencia que el sentido del poema recaiga en el lenguaje mismo. Al respecto señala Derrida (1989):

La pureza del signo sólo se advierte en el punto en el que el texto, remitiendo sólo a sí mismo, señalando su inscripción y su funcionamiento al tiempo que simulando referirse sin retorno a algo distinto de sí, "se queda sin siquiera un sentido", como lo "numérico" (p. 60).

El número es en sí mismo, en tanto no hay un referente que sea el número uno, el signo, entonces, el signo 1 es su referente, una abstracción que no tiene correlato en la realidad. Así mismo, no hay que buscar el sentido del poema fuera de sí, el lenguaje poético no es representación de la realidad es el lenguaje mismo. Esta es la primera gran revelación de Mallarmé, lo que Rancière (2014) va a establecer como la característica central del último régimen del arte (el régimen estético): el fin de la representación, es decir, la completa autonomía del arte con respecto de la realidad. Por esto en La palabra muda, para Rancière (2009, p. 21) hay tres escritores franceses que se imponen como precursores de este régimen: Flaubert y el libro sobre nada, Mallarmé y el poema como idea (que retomamos aquí para desarrollar la propuesta del Libro total), y Proust con la formación del novelista. Son tres escritores conscientes de una nueva concepción de lo que es el escritor, donde ya no impera el genio, en su inconsciente y vidente manera de crear, sino un autor consciente de lo que quiere con la obra, de lo que la obra es. Rancière lo menciona como "querer" la obra y enmarca dicha consciencia en una forma "absoluta" de ver.

Es en la correspondencia entre Flaubert y Louis Colet, donde se encuentra claramente el pensamiento de este escritor, como si fuera una confesión o una declaración de principios: 
Lo que encuentro bello, lo que querría hacer, es un libro sobre nada, un libro sin ligaduras exteriores que se sostendría a sí mismo por la fuerza interna de su estilo, como la tierra se sostiene en el aire sin ser sostenida; un libro que casi no tuviera tema, o en el que el tema, de ser posible, fuera, prácticamente invisible. Las obras más bellas son aquellas en las que se encuentra menos materia; hay tanto más belleza, cuanto más se acerca la expresión al pensamiento, cuanto más la palabra se le adhiere y desaparece. Creo que estas son las vías del porvenir en el arte. (Citado por Rancière, 2009, pp. 137-138).

También es de Flaubert de donde toma Rancière la idea de lo "absoluto", pues en la misma carta señala que desde el punto de vista del "arte puro" ya no hay que preguntarse por el tema de la obra, solo queda el "estilo" y es el estilo "una manera absoluta de ver las cosas". Lo absoluto será interpretado por el filósofo como lo "desligado", es la separación del arte, de su lenguaje con respecto del mundo en cuanto forma de representación de él. Al separarse de todas las formas de representación, dice Rancière, también se desliga de "todo su régimen de significación" (p. 140). En este punto coincide con la interpretación que Derrida hace de Mallarmé, en tanto es la pureza del signo, como pureza del significado (blancura) lo que lleva a la pérdida del sentido (silencio).

Rancière estudia la poética de Mallarmé desde la perspectiva de la pérdida de significado en términos generales, desde el simbolismo y su relación con los presupuestos románticos que defienden la autonomía del arte, y no desde la idea del Libro total (tan semejante al "libro sobre nada" de Flaubert), que es la intención de este apartado por su relación con Martínez. No obstante, la importancia de mencionar a Rancière, como a Derrida, radica en el énfasis que queremos dar a la multiplicidad de recursos y técnicas de la poética de Mallarmé en La nueva novela como piezas angulares que determinan su estructura, como ya se ha mencionado varias veces: la autonomía del arte, el fin de la representación, el lenguaje poético como aquel que deriva de, y cuya intención no puede ser más que el lenguaje mismo. Algo que sin duda retoma del romanticismo alemán y que se puede resumir en esta cita de Novalis que hace Rancière: "Es un error prodigiosamente ridículo el pensar, como lo hace la gente, que se habla en razón de las cosas. Todos ignoran lo que es propio del lenguaje, a saber, que no se ocupa, sencillamente, más que de sí mismo" (Rancière, 2009, p. 59).

Por el exceso de intertextos, es arriesgado aseverar una influencia predominante sobre la nueva novela, un hipotexto en términos de Genette. Sin embargo, lo que diferencia la presencia intertextual de Mallarmé, de los otros, es el ambicioso proyecto, por no decir imposible, de la idea del libro total. De hecho, no es una idea muy clara, pero podemos dimensionarla con La nueva novela que bien podría ser la materialización del libro total en cuanto pretende abarcar todas las esferas del universo cognoscible: matemáticas, física, literatura, filosofía, política, literatura, artes, música, desde un juego que parece ser infinito, o al menos, tiene unas posibilidades infinitas de interrelación entre sus partes. Mallarmé y Martínez son igual de excén- 
tricos en sus ambiciones poéticas, que son menos excentricidades y más intuiciones fuertes sobre lo que sería una renovación poética.

A pesar de la distancia cronológica entre Mallarmé y Martínez, y si mantenemos al margen el aspecto contexto sociocultural en el que se publica La nueva novela, podemos observar que la influencia de Mallarmé es mucho más importante que las demás referencias intertextuales de esta obra dado que como hemos demostrado es el eje principal que articula el texto. Teniendo en cuenta que, como se explicó a lo largo de este texto, La nueva novela tiene como estructura las ideas de: desestabilización del concepto de realidad, de autor, del Libro como contenedor de significados para ser él parte del significado, lo cual nos lleva a la materialidad del libro y del signo, así como el carácter metapoético, entre otros, nos llevan a considerar que dicha estructura equivale a los presupuestos mallarmeanos, utilizados intencionalmente por Martínez. La idea es la misma, la diferencia está en los recursos de los que se vale Martínez para expandir dicha idea, que son mucho más amplios que aquellos con los que podía contar Mallarmé en el siglo XIX.

Es interesante observar que de los cinco poemas de autoría de Martínez, dos de ellos tengan una relación muy estrecha con la poética de Mallarmé, además hay que resaltar que en ningún momento lo menciona directamente, tampoco a Borges. Las similitudes entre ambos las encontramos también en el artículo de María José Jara "Una lectura de Guillén y Martínez, lectores de Mallarmé" (Jara, 2007) quien también menciona la pureza del signo y la desaparición del autor como centrales en la poética mallarmeana en conjunción con la de Martínez. La diferencia, por la distancia cronológica entre los poetas, también es clara, la intención de Martínez no dista mucho de la de Mallarmé, pero hay otro contexto, otras preocupaciones y sobre todo otros medios para embarcarse en la idea de una renovación poética tanto en lo puramente lingüístico como fuera de él. Lo que en Mallarmé queda como un esbozo, una idea del Libro total a mitad de camino, en Martínez parece materializarse: la complejidad en temas, técnicas e intertextos que se presentan en La nueva novela se entienden como la totalidad: el mundo que podemos conocer. Finalmente se desarrolla la idea de que ante la imposibilidad de abarcarla (o por abarcarla realmente en su totalidad) se vuelve a la nada. Las ideas centrales del libro total de Mallarmé se hallan explícitas en La nueva novela, tanto en esos recursos que podríamos considerar extraliterarios: tipografía, imágenes, collage, etc., como en los estrictamente literarios, especialmente en el poema "El cisne troquelado".

En el capítulo VI de La nueva novela titulado "La literatura" encontramos la siguiente secuencia: una página en blanco (titulada así), el poema "El cisne troquelado", y en las siguientes páginas los textos e imágenes referidos a "Observaciones sobre el canto de los pájaros”, otro poema de Martínez. En estos poemas se hace referencia a la poética de Mallarmé que ya hemos señalado hasta ahora, por lo que consideramos que no es solo un intertexto o un homenaje al poeta francés, es la revalidación de una concepción del lenguaje poético. Veamos entonces de qué manera se explicita en el poema. 


\section{El cisne troquelado}

"El cisne Troquelado" (Martínez, 1977, p. 87) se divide en tres partes, la primera corresponde a "La búsqueda". Allí aparece en primera instancia el componente esencial con que identificamos a Mallarmé: la página en blanco y la apertura que esta conduce al texto y su proceso: manuscrito, texto corregido y lectura. La página en blanco como una condición de posibilidad, la naturaleza del signo.

\section{EL CISNE TROQUELADO}

\section{I (La Búsqueda)}

La página replegada sobre la blancura de sí misma.

La apertura del documento cerrado: (EVOLUTIO LIBRIS).

El pliego / el manuscrito: su texto corregido y su lectura.

La escritura de un signo entre otros signos.

La lectura de unas cifras enrolladas.

La página signada / designada: asignada a la blancura.

La segunda parte "El encuentro" sigue siendo una corroboración de la poética mallarmeana: "Nombrar / signar / cifrar: el designio inmaculado:/ su blancura impoluta: su blancor secreto: su reverso blanco". Estos versos, como si fueran una paráfrasis de las palabras de Derrida sobre Mallarmé, nos remiten a una relación entre el nombre, el signo y el número, términos autorreferenciales, de ahí la pureza: "designio inmaculado, blancura impoluta..."; y con la pureza el silencio. A continuación la disolución del autor: "la página signada con el número de nadie:/ el número o el nombre de cualquiera: (LA ANONIMIA no nombrada). El resto de la estrofa se refiere a una paradoja: así como la naturaleza del signo está en la página en blanco, la unidad del libro como tal, del libro total, resulta imposible: "El proyecto imposible: la compaginación de la blancura./ La lectura de unos signos diseminados en páginas dispersas./ (La Página en Blanco): La Escritura Anónima y Plural:/ El demonio de la analogía su dominio: La lectura de un signo entre unos cisnes o a la inversa”. Podríamos decir sobre esto último: la analogía por excelencia: el signe y el cygne. El cisne como el poeta.

II (El Encuentro)

Nombrar / signar / cifrar: el designio inmaculado:

su blancura impoluta: su blancor secreto: su reverso blanco.

La página signada con el número de nadie:

el número o el nombre de cualquiera: (LA ANONIMIA no nombrada).

El proyecto imposible: la compaginación de la blancura.

La lectura de unos signos diseminados en páginas dispersas.

(La Página en Blanco): La Escritura Anónima y Plural: 
El Demonio de la Analogía: su dominio:

La lectura de un signo entre unos cisnes o a la inversa.

En la tercera parte "La locura", el tema central es el borramiento del autor, en su habitual paradoja menciona a los autores (Mallarmé, Swan de Dios, Jxuan de Dios) para hacerlos desaparecer: "analogía troquelada en anonimia", de todo lo creado finalmente no queda nada. El todo y la nada será una constante de La nueva novela, porque también está en el libro total, su imposibilidad.

III (La locura)

El signo de los signos / el signo de los cisnes.

El troquel con el nombre de cualquiera:

el troquel anónimo de alguno que es ninguno:

'El Anónimo Troquel de la Desdicha':

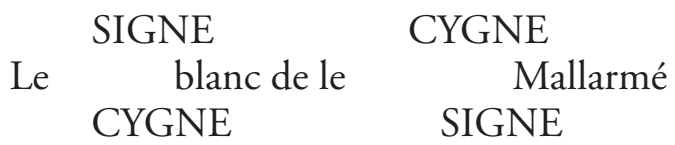

(Analogía troquelada en anonimia):

el no compaginado nombre de la albura:

la presencia troquelada de unos cisnes: el hueco que dejaron:

la ausencia compaginada en nombre de la albura y su designio:

el designio o el diseño vacío de unos signos:

el revés blanco de una página cualquiera:

la inhalación de su blancura venenosa:

la realidad de la página como ficción de sí misma:

el último canto de ese signo en el revés de la página:

el revés de su canto: la exhalación de su último poema.

(¿Y el signo interrogante de su cuello (?) ?:

reflejado en el discurso del agua: $(\dot{i})$ : es una errata).

(¿Swan de Dios?)

(¡Recuerda Jxuan de Dios!): (¡Olvidarás la página!)

y en la suprema identidad de su reverso

no invocarás nombre de hombre o de animal:

en nombre de los otros: ;tus hermanos!

también el agua borrará tu nombre:

el plumaje anónimo: su nombre tañedor de signos

borroso en su designio

borrándose al borde de la página... 
Miralles (2004, p. 75), en su tesis doctoral, analiza la obra de Martínez desde la Teoría de la Enunciación, señalando, una vez más el carácter intertextual y metapoético de La nueva novela. Dado el contexto sociopolítico y los recursos empleados en este libro Miralles considera que esta obra de Martínez es disruptiva por la "persistente desestabilización del concepto de realidad". En el análisis de "El cisne troquelado" nos muestra uno de los recursos más interesantes de Martínez: la desaparición del hablante:

El hablante se encuentra configurado en su grado cero de presencia formal. Se trata de un hablante formalmente indeterminado, cuya 'presencia subrepticia' le imprime a la frase un carácter de proposición asertiva impersonal (p. 75).

En otras palabras, en el poema desaparece el "yo poético" (algo que ya se había explicado en el primer capítulo, pero al hacerlo Araya alude a la desaparición del yo lírico a cambio de un lenguaje impersonal propio de la ciencia, las matemáticas y la lógica) y este recurso permite privilegiar el texto, lo dimensiona y manifiesta el carácter significante de la materialidad del texto: el signo, la página en blanco, la página como tal. En suma, diríamos recordando a Chartier (1992) se refiere a la materialidad del libro como parte del significado. Nuevamente retornamos a la idea del libro total de Mallarmé. Con respecto a la metapoética presente en Martínez (y Mallarmé) es otra manera de confluir en lo que ya se había mencionado: el texto que habla de sí mismo, que no es otra cosa que lenguaje, el poema que habla sobre la poesía en sí, es decir, el poema que es idea y no solo dato sensible. De ahí que Araya (2006) insista en "el intelecto", en la exigencia de un lector activo desde el conocimiento y no solamente desde la idea.

El poema como idea, el arte como idea, propio del Romanticismo y del Simbolismo es la apertura al arte conceptual y a lo que podemos llamar arte contemporáneo cuando nos referimos a performances, instalaciones, ready-made, objet trouvé, etc. Martínez, sin duda retoma el legado de todas estas propuestas artísticas en las que los géneros, como el autor, también se diluyen, incluso desaparece el "yo lírico". Para Miralles, en "El cisne Troquelado" y como alusión directa a Mallarmé, "El hablante lírico' desaparece para acceder al absoluto" (2004, p. 83). El absoluto es la insistencia a la necesidad de la pureza, a lo esencial de la poesía que es el lenguaje.

\section{El canto de los pájaros}

En la página siguiente a "El cisne troquelado" encontramos otra fuerte relación con la poética de Mallarmé, se trata de la música. En la página 88 (Martínez, 1985) solo hay una imagen dividida en dos: en la parte de arriba una partitura y en la de abajo una variedad de aves entonando melodías. En la página 89 está el texto sobre el pajarístico o el canto de los pájaros. Como en el caso de "El cisne troquelado", es un texto que podría ser leído como un poema, pero tiene elementos que nos alejan 
tanto de su forma, como del lirismo propio de los textos versificados. De entrada, el título es bastante largo, complejo e inquietante: "Observaciones relacionadas con la exuberante actividad de la 'confabulación fonética' o 'lenguaje de los pájaros' en las obras de J.P. Brisset, R. Roussel, M. Duchamp y otros". Allí no hay alusión alguna a Mallarmé, sino a dos escritores y un artista plásticos de los que habría que indagar el motivo por el que están ahí. Me apresuro a decir que es para desorientar al lector y con ironía decir que Mallarmé se encuentra en esos "otros", pues claramente el texto nos remite a él. Si en "El cisne troquelado" aparece la pureza del poema y la página en blanco como ejes principales, en "Observaciones..." todo apunta a la música.

El texto está dividido en cinco partes que bien podrían ser estrofas, porque como se dijo antes está en verso, de no ser porque hay una enumeración de cada una de ellas, con un lenguaje que parece más un conjunto de premisas, descripciones a la manera de un texto científico o un cuestionario en el que hay que seleccionar la respuesta correcta. Veamos, entonces su relación con la música.
a). A través de su canto los pájaros
comunican una comunicación
en la que dicen que no dicen nada

En este apartado Martínez la música es el canto de los pájaros y con este vuelve al silencio como función del lenguaje, tal como se explicó en "El cisne troquelado", dado que es una característica del lenguaje no representativo, del lenguaje cuyo sentido está en el lenguaje mismo. No fuera de él. Sería un lenguaje intrínseco, mudo, porque el desarrollo del lenguaje, sabemos, solo es posible con la interacción del sujeto con el mundo externo.
b). El lenguaje de los pájaros
es un lenguaje de signos transparentes
en busca de la transparencia dispersa de algún significado.

Aquí también la transparencia como equivalente a la pureza, el lenguaje de los pájaros es el lenguaje de la poesía. La pureza entendida de la misma manera que en "El cisne troquelado".

c). Los pájaros encierran el significado de su propio canto en la malla de un lenguaje vacío; malla que es a un tiempo transparente e irrompible.

d). Incluso el silencio que se produce entre cada canto es también un eslabón de esa malla, un signo, un momento del mensaje que la naturaleza se dice a sí misma. 
Alusión al lenguaje en sí mismo, la malla es el silencio, el sentido se repite porque al referirse al lenguaje de los pájaros el sentido del texto se vuelve críptico, pues no es distinto a lo que ya había dicho en "El cisne troquelado".

e. Para la naturaleza no es el canto de los pájaros

ni su equivalente, la palabra humana, sino el silencio,

el que convertido en mensaje tiene por objeto

establecer, prolongar o interrumpir la comunicación

para verificar si el circuito funciona

y si realmente los pájaros se comunican entre ellos

a través de los oídos de los hombres

y sin que estos se den cuenta.

Al mencionar a la naturaleza, el lenguaje es producto de esta y no un artificio humano, aunque el lenguaje de los humanos sea equivalente al lenguaje de los pájaros, se comunican entre sí, pero "sin que estos [los hombres] se den cuenta". Es decir, no es el lenguaje materno el que comunica, el que se equipara al de los pájaros, es el lenguaje de la poesía.

Al final de la página hay una nota aclaratoria (estas notas generalmente no aclaran nada) y en donde se reitera lo ya dicho: el lenguaje de la poesía es el canto de los pájaros: la música. Es aquí donde vemos la presencia de Mallarmé. En "Un golpe de dado...", en el prefacio, el poeta menciona cómo la página en blanco constituye una unidad, así también un verso o una línea perfecta, el papel, los trazos sonoros, los versos "son subdivisiones prismáticas de la idea". Ya sabemos que para Mallarmé el lenguaje poético es idea, por lo que hay que indagar qué clase de idea es, puesto que no puede ser la idea como concepto, por lo que dice: "Debo ańadir que de este empleo desnudo del pensamiento con retiradas, prolongamientos y escapes, y de su dibujo mismo, resulta para el que quiere leer en voz alta, una partitura", las letras de molde, las variaciones en el espacio contribuyen a esa musicalidad que es la idea.

La idea, entonces, será expresada a través de la música del lenguaje poético, no del concepto, pero esto en vez de llevarnos a la lírica, nos lleva a la prosa, pues es el camino que traza el verso libre y el poema en prosa, en palabras de Mallarmé:

Hoy, sin presumir del futuro que saldrá de aquí (nada o quizá un arte), reconozcamos fácilmente que la tentativa participa, de repente, de las búsquedas particulares requeridas por nuestro tiempo: el verso libre y el poema en prosa. Dicha reunión se cumple bajo una influencia que sé extranjera: la de la Música escuchada en los conciertos (p. 12).

"La idea de la poesía es la prosa" dirá Benjamín, que cita Rancière con relación a la noción de idea en Mallarmé, puesto que todo va encadenado y es el simbolismo el que entra en esos terrenos de reforma poética: la música, la poesía como el 
lenguaje detrás de la literatura y de los demás géneros, el verso libre, la prosa, la idea. Rancière señala:

Para que surja "la noción pura", el acto poético debe operar musicalmente (...) Porque lo propio de la música es hacer desaparecer al mismo tiempo la densidad de las cosas y la organización representativa de las palabras. Solo la música propone un lenguaje estructuralmente purificado de la representación, en el que esta se desvanece en favor de la vibración, es decir, de la espiritualización de la materia. Está "cerca de la Idea" porque es la tumba de la imagen y del reportaje (2009, p.172). ${ }^{3}$

\section{Conclusión}

Es difícil pensar que se puede hacer un análisis exhaustivo de la poética de Martínez, al analizar a profundidad uno de los intertextos, surgen otros y otros. Queda pendiente, por ejemplo, la relación con Borges, con Lewis Carroll y tantos otros, mencionados o no, existentes o no. Los procedimientos seńalados y los autores explicitados se tomaron con el fin de hacer énfasis en la visualidad de La nueva novela. Son elementos que nos permiten entender de qué manera Martínez rompe con la lectura habitual de un texto, la cantidad de direcciones, asociaciones, interpretaciones, tiempos que un lector puede tomar para seguir el libro de principio a fin o en el orden que desee, quizás ningún orden, también es posible no llegar a un final del libro. Consideramos que la ambiciosa apuesta de Martínez, similar a la de Mallarmé, bien pueden compartir las palabras de Valéry (citado por Blanchot, 2005) cuando dice que Mallarmé logró hacer de la página en blanco un cielo estrellado.

\section{Referencias}

Agamben. (2011). "¿Qué es un dispositivo?». Sociológica, 26(73), 249-264.

Araya, P. (2006). "L'imagination matérielle: écriture, texte, page, livre. Pour une approche de La nueva novela de Juan Luis Martínez". file://D:/Usuario/Downloads/L_imagination_materielle_ecriture_texte.pdf.

Blanchot, M. (2005). El libro que vendrá. Madrid: Trotta.

Chartier, R. (1996). El mundo como representación. Historia cultural: entre práctica y representación. Barcelona: Gedisa.

Derrida, J. (1989). "Mallarmé” (Francisco Torres, trad.). Anthropos, Revista de Documentación Cientifica de la Cultura, Suplemento, 13 pp. 59-69.

Elizondo, S. (2008). Stéphane Mallamé. CDMX: Universidad Nacional Autónoma de México.

Gache, B. (2006). "La poética visual como género híbrido: entre las fronteras entre leer y ver". Páginas de guarda: revista de lenguaje, edición y cultura escrita. (2) pp. $137-152$.

3 Lo que está en comillas es lo que cita de Mallarmé. 
Herrera, J. (2007). "La nueva novela de Juan Luis Martínez: poesía protohipertextual en el contexto de la videósfera". Acta Literaria, 35, 9-27.

Jara, M.J. (2007). "Una lectura de Guillén y Martínez: lectores de Mallarmé"recuperado de https://web.uchile.cl/.../0,1255,SCID\%253D21061\%2526ISID\%253D731,00.html

Liquete, C.L. (2000). "Una lectura de múltiples lecturas en torno a Un Coup de dés... de Mallarmé". Recuperado de

http://www.lapaginadenadie.com/t2/page3.asp? Id=87804\&Rf $=34 \& \mathrm{R}$ $\mathrm{t}=3 \& \mathrm{~Np}=342$

Mallarmé, S. (2010). Un golpe de dados jamás abolirá el azar. Recuperado de https:// issuu.com/pleamar/docs/golpe_de_dados

Martínez, J.L. (1985). La nueva novela. Recuperado de http://www.juanluismartinez.cl

(1978). La poesía chilena. Recuperado de http://www.juanluismartinez.cl

Miralles, D. (2004). Poéticas de la postmodernidad: literatura chilena neovanguardista durante la dictadura militar (1973-1990). (Tesis doctoral). Universidad de Oregon.

. (s.f.). El cisne y el signo: nota sobre la metapoesía en un texto de Juan Luis Martínez. Recuperado de: http://www.archivochile.com/tesis/09a_narrpoe/09a_ narrpoe00004.pdf

Rancière, J.J. (2014). El reparto de lo sensible. Buenos Aires: Prometeo

. (2009). La palabra muda. Buenos Aires: Eterna cadencia

Rioseco, M. (2013). Maquinarias deconstructivas: poesía y juego en Juan Luis Martínez, Diego Maquieira y Rodrigo Lira. Santiago: Cuarto Propio

Valente, I. (20 de noviembre de 1977). "La poesía experimental de Juan Luis Martínez". El Mercurio. 